\title{
PHYSIOTHERAPY IN COMBINATION WITH MULTIMODAL INTERVENTIONS REDUCE IN ADULT PATIENTS CHRONIC NECK PAIN-REVIEW
}

\author{
Enkeleda Sinaj ${ }^{1^{*}}$, Fatjona Kamberi ${ }^{2}$ \\ ${ }^{1 *}$ Faculty of Technical Medical Sciences, University of Medicine, Tirana, Albania; \\ ${ }^{2}$ Research Center of Public Health, Faculty of Health, \\ University of Vlora "I. Qemali", Vlora, Albania;
}

*Corresponding Author Enkeleda Sinaj, e-mail: sinaj@hotmail.it; enkeleda.sinaj@umed.edu.al; fatjonakamberi@gmail.com; fatjona.kamberi@univlora.edu.al;

Received November 2020; Accepted December 2020; Published January 2021;

DOI: https://doi.org/10.31407/ijees11.111

\begin{abstract}
Chronic neck pain is one of the most frequent musculoskeletal disorders in adults. It not only disrupts a person's quality of life but there is also with very high economic costs. The effects of physiotherapy in this problem are still unclear, and more the combination of physiotherapy with other treatment methods. The purpose was to review the literature in relation to the effectiveness of the combination of physiotherapy with other treatments as an important alternative in the treatment of chronic neck pain in adult patients. The research included the electronic database of Ovid PubMed, PEDro, NLM Tools, and CINAHL. Seven studies on the effects of physiotherapy in combination with other treatments in chronic neck pain were included in the review. Adults patients, only randomized clinical trials, and the studies published in the past two years were the inclusion criteria. The variable that was taken into account after primary treatment was the reduction of chronic neck pain. The study results showed that clinical studies were limited, even if the multimodal intervention may be an effective intervention for chronic neck pain patients. The review showed that physiotherapy has satisfactory effects in the treatment of chronic neck pain in combination with multimodal interventions but there is not enough evidence, due to the small number of trials included in the review.
\end{abstract}

Keywords: Neck pain, physiotherapy, multimodal, intervention, clinical trials. 